\title{
O Mito da conversibilidade
}

\author{
The myth of convertibility
}

LUIZ GONZAGA BELLUZZO*

RICARDO CARNEIRO**

\begin{abstract}
RESUMO: Uma crítica à proposta de tornar o real conversível. A conversibilidade não elimina a hierarquia de moedas no espaço global e o premio de risco pago pelas moedas não conversíveis.
\end{abstract}

PALAVRAS-CHAVE: Moeda; conversibilidade; hierarquia de moedas.

ABSTRACT: A critique to the proposal of making the real convertible. The convertibility does not eliminate the hierarchy of currencies in the global space and risk premium paid by the non-convertible currencies.

KEYWORDS: Currency; convertibility; hierarchy of currencies.

JEL Classification: E50.

A conversibilidade da moeda nacional tem sido um tema recorrente nos debates sobre a economia brasileira. A mais recente contribuição vem do economista Pérsio Arida por meio de dois artigos "Por uma moeda plenamente conversível" e "Ainda sobre a conversibilidade", o primeiro publicado no jornal Valor de 12 de novembro de 2002 e republicado conjuntamente com o segundo na Revista de Economia Política de julho/setembro de 2003. O argumento central dos artigos é o de que é imprescindível fazer do real uma moeda plena e legalmente conversível, para reduzir as elevadas taxas de juros vigentes hoje no país e assegurar o seu estatuto de reserva de valor. A tese soa um tanto estranha para uma economia que ampliou de maneira radical a abertura financeira ao longo da década de 90. Desde logo, porque não atribui a devida importância à enorme mudança operada no marco regulatório da conversibilidade desde o início dos anos 90. Foi exatamente

\footnotetext{
* Professor titular do Instituto de Economia da Universidade de Campinas - Unicamp, Campinas/SP, Brasil.E -mail: belluzop@aol.com.

* Diretor executivo do Centro de Estudos de Conjuntura e Política Econômica da Universidade de Campinas - Unicamp. E mail: carneiro@eco.unicamp.br. Submetido: outubro 2003; aceito: novembro 2003.
} 
essa transformação, associada a uma conjuntura internacional favorável, que permitiu ao país receber significativos fluxos de capitais entre 1992 e 1998 com taxas de risco-país declinantes, que, em seus melhores momentos, antes da crise asiática, alcançaram os 450 pontos. No entanto, o autor alega que essa conversibilidade ampliou-se de fato, mas não de direito, o que significa dizer que pode ser revertida por via administrativa anulando todo o avanço obtido.

Vejamos em detalhe o argumento, a sua crítica e as possível alternativas.

\section{O ARGUMENTO}

Com a palavra o autor:

"O primeiro artigo sobre conversibilidade concentrou-se no processo de arbitragem entre juros internos e juros externos. Em regimes de conversibilidade restrita, o risco de imposição, por via administrativa, de restrições à liberdade de capitais é compensado por meio de uma depreciação excessiva da moeda doméstica ou de taxas de juros em reais mais altas do que deveriam ser ou ambas. Neste artigo exploro outro fator, também derivado da conversibilidade restrita, a aumentar o prêmio de risco na formação das taxas de juros internas. É que o estado de confiança nos mercados financeiros depende, em boa medida, da interpretação das políticas anunciadas pelo Banco Central. A manutenção de regimes de conversibilidade restrita mesmo com taxas de câmbio flutuantes sinaliza urbi et orbi desconfiança na moeda como reserva de valor. Como conseqüência, cresce o risco percebido e, portanto, o superávit fiscal primário necessário para estabilizar a moeda ao longo do tempo.”

Segundo Arida, a razão histórica para que a conversibilidade tenha sido restrita esteve associada à incapacidade da moeda nacional de exercer a função de reserva de valor devido à inflação crônica, motivo parcialmente suprimido pela estabilidade obtida nos últimos anos. Sempre houve, e há, o temor de que a supressão dos entraves à conversibilidade implique uma transformação de parcela expressiva da poupança doméstica em aplicação em moeda estrangeira. Apesar disso, ele insiste que esse é apenas um lado do problema, pois, se a eliminação de restrições fosse percebida como segura e permanente, implicaria uma oferta ampliada de divisas. A tese de Arida se apóia, pois, num processo virtuoso de confidence building.

Ao discutir a taxa de juros paga pelo país, o autor assume a hipótese de que a existência de uma ameaça à suspensão da conversibilidade introduz um prêmio adicional àquele relativo ao risco de crédito cobrado pelos investidores estrangeiros. Assim, a taxa de juros em dólares seria composta pela taxa básica de juros na moeda reserva somada a um risco-país, o qual poderia ser decomposto em duas partes: o risco de crédito ou de default e o risco administrativo ou de racionamento de divisas. Com a eliminação deste último, a taxa de juros cairia, diminuindo o risco-país, a taxa de juros em dólares e, por arbitragem, a taxa de juros em reais. 
Além da questão do patamar quantitativo dos juros, o autor chama a atenção para o fato de que a remoção dos empecilhos à conversibilidade terminaria por eliminar também a noção de risco soberano. Ou seja, sendo a compra e venda de divisas integralmente livre, existiriam apenas tomadores com distintos riscos de crédito.

Examinando os efeitos prováveis da ampliação da conversibilidade, o autor rechaça a idéia de que esta produziria uma desvalorização significativa da moeda nacional. Para ele isso só ocorreria se a taxa de câmbio estivesse muito distante do equilíbrio. Não sendo isso verdadeiro, pergunta-se, por que alguém se disporia a continuar comprando divisas mesmo com a moeda local desvalorizada? A única razão seria o questionamento da capacidade da moeda local em atuar como reserva de valor. Essa desconfiança seria, contudo, eliminada ou reduzida diante da conversibilidade plena e da queda da taxa de juros.

Embora reconheça que a liberalização irrestrita pode ocasionar volatilidade excessiva e bolhas especulativas, conduzindo a taxas de câmbio excessivamente valorizadas ou desvalorizadas, como, aliás, tem ocorrido nos últimos anos, o autor nega que a restrição à conversibilidade possa minimizar o problema. Para evitá-lo, sugere que o Banco Central atue diretamente no mercado de câmbio, comprando e vendendo divisas, e que se utilize, quando necessário, uma tributação dos fluxos de capitais com alíquota uniforme. O autor chega a afirmar que o fato de o Banco Central atuar no mercado de câmbio por meio de substitutos da moeda estrangeira, como títulos indexados em dólares ou operações no mercado futuro, apenas exacerba a desconfiança em relação à moeda nacional.

\section{A CRÍTICA}

As críticas ao argumento da conversibilidade podem ser formuladas em planos distintos. De um ponto de vista mais geral, a conversibilidade plena não elimina as fraquezas genético-estruturais da nossa moeda, como a inconversibilidade efetiva. Isso significa que a remoção de fato ou de direito das restrições à conversibilidade no plano doméstico não torna a moeda nacional uma referência ou uma reserva de valor no plano internacional. Ou seja, num horizonte de tempo previsível, a nossa moeda não passará a denominar contratos, constituir-se em referência de preços e muito menos será demandada como ativo de reserva por terceiros países. Do ponto de vista dos residentes no país, isso se traduz no assim chamado pecado original, isto é, na impossibilidade de emissão de dívida nos mercados internacionais, denominada na sua própria moeda, dando origem ao conhecido problema do descasamento (mismatch currency).

Desse problema básico decorrem vários outros. O principal deles é a assimetria entre oferta e demanda de divisas numa economia com moeda não conversível. As razões para essa assimetria são várias, a começar pelo fato de que a livre conversão implica que os residentes procurarão transformar parcela de sua riqueza em moedas conversíveis, não por desconfiarem da moeda doméstica como reserva de valor, mas simplesmente porque há moedas reserva de maior qualidade. As teorias monetárias 
em geral, ao analisarem a globalização, descuram da existência de um prêmio de liquidez demandado pelos agentes que mantêm sua riqueza em moedas fracas. ${ }^{1}$ Além disso, há os setores endividados em moeda estrangeira que buscam fazer hedge contra o descasamento de moedas nas suas dívidas e aqueles que procuram proteger o valor de seus patrimônios em dólares, como as empresas transnacionais. A assimetria que se quer ressaltar é que, enquanto a oferta de divisas está, em grande medida determinada pelos fluxos, a demanda por divisas é função dos estoques de riqueza e dívida.

Ao não suprimir a hierarquia de moedas no espaço globalizado, a conversibilidade não elimina a razão central para o mais elevado prêmio de risco pago pelas moedas não conversíveis. Ou seja, ele é um prêmio que se paga para manter a riqueza em moedas mais frágeis. Como moedas não são bananas, em particular a moeda reserva, a sua demanda aumenta como decorrência direta da sua valorização. Ou seja, para todos aqueles que têm ativos nas demais moedas, particularmente naquelas inconversíveis, a resposta à valorização da moeda reserva é um aumento da sua procura. O inverso ocorre com as moedas menos líquidas, cuja desvalorização relativa produz uma redução da demanda.

No caso específico do Brasil a conversibilidade tampouco elimina nosso enquadramento no segmento de mercado de títulos de high yield. Ou seja, mesmo que isso possa ocorrer, levará tempo, pelo menos até que o nosso risco de crédito melhore de fato. Enquanto isso não ocorrer teremos que pagar prêmios de risco mais elevados e conviver num segmento do mercado globalizado que é por definição mais volátil.

Aliás, a subestimação do risco de crédito é outro ponto fraco do argumento de Arida ao tentar dissociar dois riscos que na prática são indissociáveis, isto é, estão correlacionados. Um país com baixo risco de crédito, no qual os indicadores de solvência e liquidez estão em patamares adequados, não possui de fato, embora possa ter de direito, risco de racionamento de divisas. Ao revés, um país com elevado risco de crédito pode ter, de fato, um elevado risco de racionamento de divisas, embora ele não exista de direito. O que se pode dizer é que o risco de racionamento de divisas é secundário ante o risco de crédito.

Há ainda a considerar a capacidade real de intervenção das autoridades econômicas locais para estabilizar a taxa de câmbio, como quer o autor. Certamente o baixo nível de reservas é o maior fator limitante para essas interferências. Por sua vez, a reconstituição dessas reservas terá um custo fiscal expressivo por terem de se fundar em operações de esterilização, com ampliação da dívida pública ou um indesejável aumento do superávit fiscal. É dispensável relembrar que ambos já são muito elevados.

Resta a examinar a possibilidade de que todos os argumentos críticos listados acima se mostrem equivocados. Ou seja, que a instituição da conversão de direito

\footnotetext{
${ }^{1}$ Num mundo marcado pela mobilidade de capitais e taxas de câmbio flutuantes, as ( $\left.\mathrm{n}-1\right)$ moedas do sistema podem ser hierarquizadas conforme seus riscos e prêmios de liquidez em relação à moeda reserva.
} 
promova uma entrada expressiva de capitais. O primeiro efeito previsível é uma apreciação da moeda nacional com deterioração da balança de transações correntes. A outra, como a experiência recente demonstra, será certamente a formação de bolhas de ativos, dada a estreiteza dos mercados financeiros e cambiais locais, com grande probabilidade de ocorrência de crises.

\section{A ALTERNATIVA}

Uma das conclusões de maior relevância da argumentação acima é a de que a conversibilidade doméstica da moeda, de direito, como quer Arida, deverá promover o seu enfraquecimento, como, aliás, ocorreu nos últimos anos, ante um marco regulatório crescentemente permissivo. Um exemplo ilustra a afirmativa: após mais de uma década de liberalização, o país ainda continua com uma péssima classificação de risco (subinvestment graded). Assim, a crítica à proposta da conversibilidade sugere inclusive que se tome uma direção contrária e se limite o grau de conversibilidade da moeda nacional, tanto por razões estruturais - inconversibilidade de fato - quanto por motivos conjunturais, como excesso de endividamento externo e interno e escassez de divisas.

Para se melhorar a posição da moeda nacional e se reduzir de maneira consistente o risco de crédito do país seria mais produtivo retomar, em algum grau, o controle sobre o fluxo de divisas no país, estabelecendo em primeiro lugar, uma regulação sobre entradas e saídas de capitais especulativos. Esse controle poderia, por sua vez, constituir-se na condição necessária para eliminar a arbitragem entre taxas de juros externas e internas, permitindo a sua redução imediata. Os controles permitiriam também a perseguição de uma taxa de câmbio compatível com a geração de um saldo global de balanço de pagamentos que pudesse se transformar em acumulação de reservas, cujo custo de carregamento em moeda nacional seria reduzido em razão da queda da taxa de juros. 